\title{
Proteomic and Glycomic Characterization of Rice Chalky Grains Produced Under Moderate and High-temperature Conditions in Field System
}

Kentaro Kaneko ${ }^{1}$, Maiko Sasaki ${ }^{1}$, Nanako Kuribayashi ${ }^{1}$, Hiromu Suzuki ${ }^{1}$, Yukiko Sasuga ${ }^{2}$, Takeshi Shiraya ${ }^{2,3}$, Takuya Inomata', Kimiko Itoh', Marouane Baslam ${ }^{1}$ and Toshiaki Mitsui ${ }^{1,2^{*}}$

\begin{abstract}
Background: Global climate models predict an increase in global mean temperature and a higher frequency of intense heat spikes during this century. Cereals such as rice (Oryza sativa L.) are more susceptible to heat stress, mainly during the gametogenesis and flowering stages. During periods of high temperatures, grain filling often causes serious damage to the grain quality of rice and, therefore, yield losses. While the genes encoding enzymes involved in carbohydrate metabolism of chalky grains have been established, a significant knowledge gap exists in the proteomic and glycomic responses to warm temperatures in situ. Here, we studied the translucent and opaque characters of high temperature stressed chalky grains of 2009 and 2010 (ripening temperatures: 24.4 and $28.0^{\circ} \mathrm{C}$, respectively).
\end{abstract}

Results: Appearance of chalky grains of both years showed some resemblance, and the high-temperature stress of 2010 remarkably extended the chalking of grain. Scanning electron microscopic observation showed that round-shaped starch granules with numerous small pits were loosely packed in the opaque part of the chalky grains. Proteomic analyzes of rice chalky grains revealed deregulations in the expression of multiple proteins implicated in diverse metabolic and physiological functions, such as protein synthesis, redox homeostasis, lipid metabolism, and starch biosynthesis and degradation. The glycomic profiling has shown slight differences in chain-length distributions of starches in the grains of 2009-to-2010. However, no significant changes were observed in the chain-length distributions between the translucent and opaque parts of perfect and chalky grains in both years. The glucose and soluble starch contents in opaque parts were increased by the high-temperature stress of 2010, though those in perfect grains were not different regardless of the environmental changes of 2009-to-2010.

Conclusion: Together with previous findings on the increased expression of a-amylases in the endosperm, these results suggested that unusual starch degradation rather than starch synthesis is involved in occurring of chalky grains of rice under the high-temperature stress during grain filling period.

Keywords: Amylase, Chaperones, Endosperm, Environment, Heat shock protein, High-temperature stress, Late embryogenesis abundant (LEA) protein, Grain chalkiness, Starch granule, Stress-related protein

\footnotetext{
* Correspondence: t.mitsui@agr.niigata-u.ac.jp

'Graduate School of Science and Technology, Niigata University, Niigata

950-2181, Japan

${ }^{2}$ Department of Applied Biological Chemistry, Niigata University, Niigata

950-218, Japan

Full list of author information is available at the end of the article
} 


\section{Background}

Global climate change is one of the most serious environmental threats we face today. Since the early 20th century, the average surface temperature of the Earth has unusually increased by about $0.8{ }^{\circ} \mathrm{C}$ coupled with the rapid warming of $0.6{ }^{\circ} \mathrm{C}$ over the past three decades. Climate change is also projected to have significant impacts on crop production (IPCC 2013). In $80 \%$ of the rice harvested areas in Japan climate variability was more important and the explanation is on account of temperature variability (Ray et al. 2015). For every $1{ }^{\circ} \mathrm{C}$ increase in temperature, there was a $6.6 \%$ decrease in yield from the current values for early rice, $5.2 \%$ for late rice, and $8.2 \%$ for single-cropped rice (Defeng and Shaokai 1995). The abnormal high temperature during rice endosperm development and grain filling periods can change the chemical ingredients of rice caryopses such as starch and storage proteins and the contents of fatty acid, thus causing a decrease in grain yield, quality and, hence, price. The occurrence of chalky grains of rice is increased by high-temperature stress during grain filling (Nagato and Ebata 1965). Morita et al. (2016) showed that chalky grains of japonica cultivars have been produced under temperatures more than $26{ }^{\circ} \mathrm{C}$ during the grain-filling period. Daily mean air temperatures of $26^{\circ} \mathrm{C}$ during grain filling are becoming frequent in Japan (Usui et al. 2014). Many research groups have studied morphological characteristics of chalky grains, showing that abnormal starch granules were loosely packed in the chalky grains (Evers and Juliano 1976; Tashiro and Wardlaw 1991; Kim et al. 2000; Lisle et al. 2000; Singh et al. 2003; Ishimaru et al. 2009). Kernels with chalky have a lower density of starch granules than do vitreous ones and are more prone to breakage during milling. The surface of round-shaped starch granules in chalky grains caused by high-temperature stress had small pits occasionally (Tashiro and Wardlaw 1991). It should be noted that the feature of change of granule surface was similar to that occurring during germination (Fuwa et al. 1977). The environmental temperature at the grain filling stage has been reported to influence the starch composition in rice grains (Asaoka et al. 1984; Inouchi et al. 2000; Lisle et al. 2000; Umemoto and Terashima 2002; Cheng et al. 2005; Yamakawa et al. 2007; Mitsui et al. 2016). High temperature caused a reduction in the amylose contents and changed the fine structure of amylopectin (Asaoka et al. 1984; Inouchi et al. 2000; Cheng et al. 2005), suggesting that the unusual expression of the starch synthesizing enzymes is a possible key factor causing the chalky grains of rice (Nishi et al. 2001; Tanaka et al. 2004). On the other hand, surface of the starch granules showed clear 'erosion' with multiple small pits suggesting an attack by $\alpha$-amylases (Zakaria et al. 2002; Iwasawa et al. 2009); the suppression of $\alpha$-amylase genes by RNA interference improved the appearance quality of rice grains ripened under heat stress (Hakata et al. 2012). However, the mechanism of grain chalkiness under high-temperature stress is considerably complicated and still remains poorly understood: a disorder of photosynthesis, translocation efficiency, source-sink relationship, and protein expression in ripening seeds may involve in such chalking mechanism. Many quantitative trait loci (QTLs) controlling grain appearance quality have been identified in populations derived from crosses between japonica cultivars (Tabata et al. 2007; Ebitani et al. 2008; Kobayashi et al. 2013; Ishimaru et al. 2016), between japonica and indica cultivars (He et al. 1999; Wan et al. 2005; Ishimaru et al. 2016), indica cultivars (Mei et al. 2013), and between O. sativa and O. glaberrima (Li et al. 2004). Therefore, understanding of the mechanisms of grain chalking is indispensable to develop a strategy for reducing the high rate of chalky grains under the likely scenario of global warming (Lin et al. 2014).

On the other hand, in addition to starch, proteins account for $6-10 \%$ of the dry mass and are important for the nutrition, cooking, and brewing quality of rice grains (Bressani et al. 1971; Hamaker 1994). Therefore, the importance of rice endosperm proteins should not be underestimated. The lack of perfect correlation of mRNA and protein levels during heat treatment has pushed the researchers to explore insights into the proteomic basis, since this technique provides a more direct assessment of the actual proteins performing the signaling, enzymatic, regulatory and structural functions encoded by the genome and transcriptome (EchevarríaZomeño et al. 2015). Considerable work on rice grains proteomics has been carried out using two-dimensional polyacrylamide gel electrophoresis (2D-PAGE) and gelfree-based shotgun procedures (Koller et al. 2002; Lin et al. 2005, 2014; Xu et al. 2008; Lee and Koh 2011). Nonredundant proteins of 4,172 with a wide range of molecular weight $(5.2-611 \mathrm{kDa})$ and $\mathrm{pI}$ values $(\mathrm{pH} 2.9-$ 12.6) in developing and mature grains of rice has been identified by using a label-free shotgun technique (Lee and Koh 2011). The ontology categories of 52 including the carbohydrate metabolic process, transport, localization, lipid metabolic process, and secondary metabolic process were enriched. Expression analyzes of functionally categorized protein groups showed dynamic changes of metabolisms during rice grain development. As a noteworthy observation, proteins involved in glycolysis, citric acid cycle, lipid metabolism, and proteolysis accumulated at higher levels in mature grain than those of developing stages (Lee and Koh 2011). This probably indicates that the preparation of materials required in germination occurred until the seeds were fully matured and dried.

Proteomic information of rice grains in the anthesis, ripening, and maturing stages under heat stress has been gradually accumulated. The anthesis and early ripening stages are known to be highly sensitive to heat stress. Gelbased proteomic analyzes of different genotype anthers 
prepared from rice plants treated with high $\left(38{ }^{\circ} \mathrm{C}\right)$ and control $\left(29^{\circ} \mathrm{C}\right)$ temperature at anthesis were carried out (Jagadish et al. 2008). Both cold $(19 \mathrm{kDa})$ and heat $(24 \mathrm{kDa})$ shock proteins were significantly up-regulated in a heat-tolerant genotype N22, these possibly contributing to the greater heat tolerance of N22. Heat stress (35/ $30{ }^{\circ} \mathrm{C}$ day/night) during an early stage of caryopsis development reduced the expression of starch granule-bound starch synthase (Wx) and prolamin, but enhanced the expression of dnaK-type hsp70 and glutelins in comparison with those in control temperature $\left(30 / 25^{\circ} \mathrm{C}\right.$ ) (Lin et al. 2005). In addition, heat stress response of several different cultivars including high-chalky types were analyzed, the results showing that sHSP was positively correlated with the appearance of chalky kernels (Lin et al. 2005). In recent studies, accumulation of all classes of storage proteins was increased at early filling stage under heat stress $\left(35 / 30{ }^{\circ} \mathrm{C}\right)$, whereas the prolamin accumulation was decreased at maturation and desiccation stages (Lin et al. 2010). On the other hand, Lin et al. (2014) showed that up-regulation of proteins involved in starch accumulation and down-regulation of ER proteins, PDIL 2-3 and BiP, were observed in the chalky tissue of notched-belly mutant appeared regardless of the environmental stress, employing a comparative proteomic analysis by iTRAQ (isobaric tags for relative and absolute quantification). Understanding protein expression patterns and its respective posttranslational modifications in chalky grain is of fundamental importance for targeting rice quality under temperatures variability.

In the present investigation, we characterized chalky and perfect grains of rice harvested in Niigata, central Japan, of 2009 and 2010 employing proteomic and glycomic techniques to provide a better understanding of the mechanisms of chalky formation under hot season in field conditions. 2010 was the hottest year since Japan began keeping records; on the other hand, 2009 was an average crop year. Our results provide a comprehensive view of proteome and glycomic characterization under temperature variability. We consider which proteins, possibly, involved in the grain chalking under the paddy field conditions.

\section{Results and discussion}

\section{Rice grains under high temperature showed chalky} appearance

Perfect and chalky grains of rice (cv. Koshihikari) were harvested at a paddy field of Sanjo city (Niigata, Japan) in 2009 and 2010. The average temperature of heading and ripening period of Koshihikari in $2010\left(28.0^{\circ} \mathrm{C}\right)$ was much higher than that in $2009\left(24.4{ }^{\circ} \mathrm{C}\right)$. The 1,000-kernel weight of chalky grains in 2010 (15.61 g) was apparently small compared with the 2009 chalky grains (16.97 g), but a variation of the 1,000-kernel weight of the perfect grains in 2009 and 2010 (21.62 and 21.99 g, respectively) was indistinguishable. The volumes (length $\mathrm{x}$ width $\mathrm{x}$ thickness) of 2009 perfect, 2010 perfect, 2009 chalky, and 2010 chalky grains were $29.15,28.73,23.85$ and $23.84 \mathrm{~mm}^{3}$, respectively. Thus, the size of the chalky grain was smaller than that of the perfect grain, whereas there was no difference between the sizes in 2009 and 2010 chalky grains. The decrease in rice grain length and width might be related with the reduction in average endosperm cell area observed under high temperature (Morita et al. 2005). Consequently, it has been suggested that the flow of $\mathrm{C}$ and $\mathrm{N}$ to the grain (Mohammadi et al. 2010), and insufficient supply of photosynthates from source to sink organ and carbohydrate deficit (Liu et al. 2009; Kanno and Makino 2010; Shi et al. 2013) caused by increased temperature could be causes of chalkiness.

The ratios of the opaque region to the whole area in 2009 and 2010 chalky grains were estimated to be $61.1 \pm 10.2$ and $78.4 \pm 13.6 \%(n=50)$, respectively. These results strongly suggest that the high-temperature stress further extended the chalking of grain. Starch granule morphologies of the perfect and chalky grains were analyzed by scanning electron microscopy (SEM). In the perfect grain (Fig. 1a), the starch granules were tightly packed in the endosperm cells, and the shape of starch granule was polygonal with sharp edges (Fig. 1Ca). In the chalky grain (Fig. 1b), the starch granules in the translucent part of chalky grains had similar tight packing and shape (Fig. $1 \mathrm{Cb}$ ) compared to the perfect grain. While in the opaque part, the starch granules were loosely packed, and some granules had a round shape with several small pits (Fig. 1c; c-1, 2, 3 and 4). The numerous pits were frequently observed upon the surface of round-shaped starch granules in the chalky endosperm caused by high-temperature stress of grain filling period (Evers and Juliano 1976, Tashiro and Wardlaw 1991). It is noteworthy that the present result of SEMs observation confirmed display signs of pitting on the starch granules in the chalky grains (Fig. 1c; c-1, 2, 3 and 4). The chalky zone sometimes occurs midway between the center and peripheral part of the endosperm in the developing kernels under high-temperature conditions. The ringshaped chalkiness could be a cell-specific event associated with the disruption of starch accumulation. Similar observations made for cell layers in rice endosperm showed that inadequate starch accumulation occurs from the center towards outward in the endosperms (Wada et al. 2014). The increase of the frequency of pitting in starch granules with high temperature is presumably due to the premature autolysis of starch. This is similar to the premature autolysis reported in the case of wheat and maize kernels subjected to high temperatures (Tashiro and Wardlaw 1990, 1991; Commuri and Jones 1999).

For analyzing changes in the proteome and glycome of grains, the translucent and opaque parts of chalky grains and the central parts of perfect grains were prepared as 


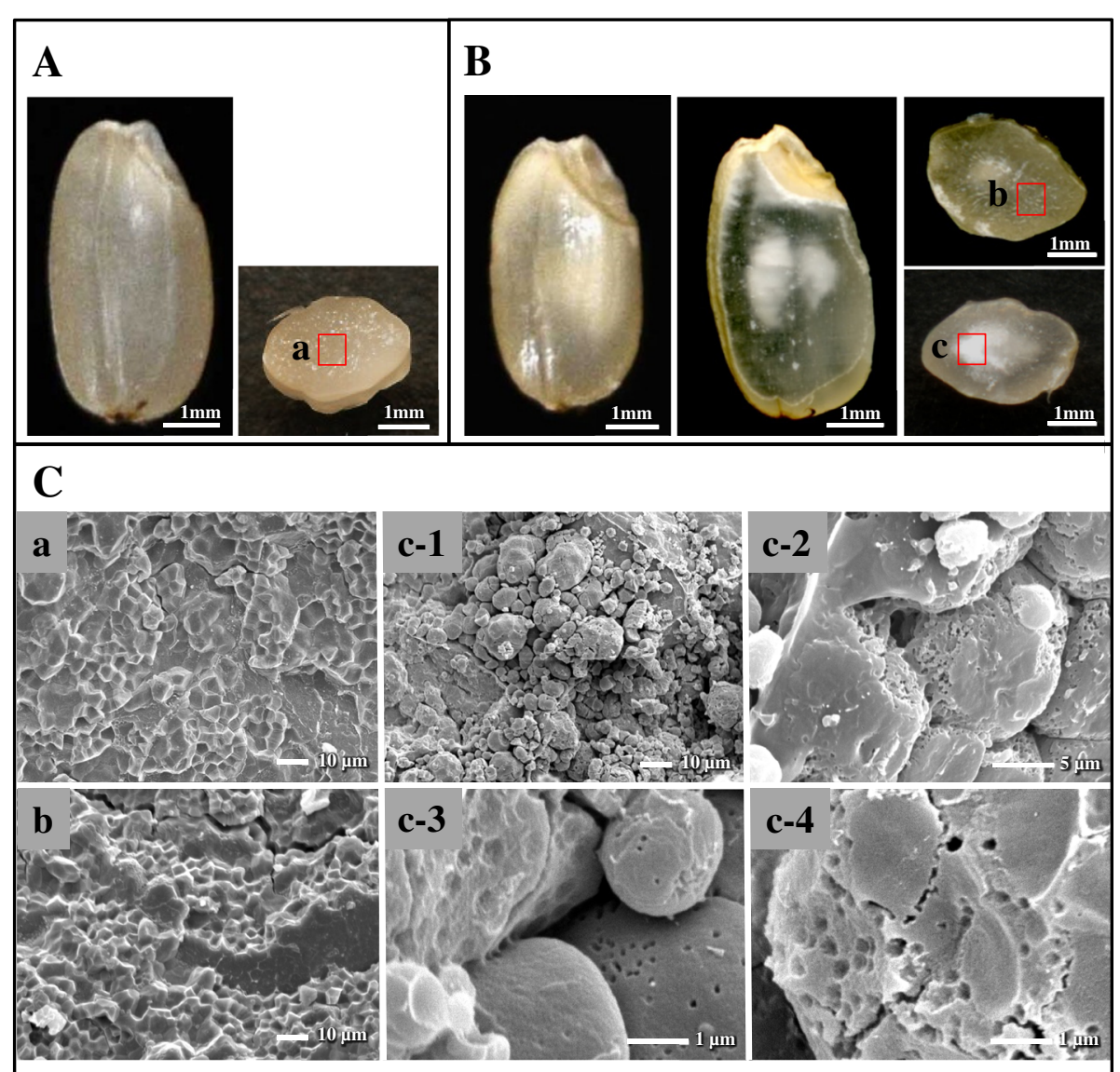

Fig. 1 Morphological characteristics of chalky grain of rice. (A) Perfect grain. Left and right panels show pictures of whole grain and horizontal slice, respectively. (B) Chalky grain. Left, whole grain; middle, vertical slice; right, horizontal slices. (C) SEM pictures. Center part of perfect grain (a), and translucent (b) and opaque (c) parts of chalky grain were subjected to SEM observation. Magnifications were x1,000 (a,b,c-1), $\times 4,000$ (c-2) and x10,000 $(c-3, c-4)$, respectively

follows: central part of perfect grain in 2009 (PG 2009), translucent part of chalky grain in 2009 (tCG 2009), opaque part of chalky grain in 2009 (oCG 2009), central part of perfect grain in 2010 (PG 2010), translucent part of chalky grain in 2010 (tCG 2010), and opaque part of chalky grain in 2010 (oCG 2010).

\section{Proteomic profile of chalky grains caused under different temperature conditions}

To characterize the proteome involved in the mechanism of grain chalking, we carried out a quantitative shotgun proteomic analysis of starchy endosperms prepared from the opaque part of chalky grains (oCG 2009 and oCG2010) and the corresponding part of perfect grains harvested in 2009 and 2010 (PG 2009 and PG2010). The extracted proteins were trypsin-digested and labeled by iTRAQ (isobaric tag for relative and absolute quantitation), followed by tandem mass spectrometry (MS/MS) analysis. Analysis of protein extracts from the different samples resulted in the detection 938 of roteins (Fig. 2a, Additional file 1: Table S1). This analysis revealed that the expression of 61 proteins, $6.5 \%$ of all identified proteins, were deregulated (more than 2.0-fold difference relative to PG control; P value $<0.05$ ) in the oCG 2010 (Fig. 2b, Additional file 1: Table S1). Among this population, 41 genes were upregulated and 20 genes were down-regulated.

To determine the biological processes affected by high temperature, an analysis of proteins using the InterProscan was carried out. This research revealed that chalkiness clearly leads to the differential expression of proteins and suggest that the energy and metabolic pathways are highly disrupted; other categories of proteins may involve in protecting the cellular damage under high-temperature stress (Fig. 2). The annotation of protein sequences using InterProScan permitted to fall them into 33 categories. In the molecular functional group, the identified proteins; ribosomal, redox, LEA and HSP were ranked at the top of the category occupancy, suggesting that the relevant functions were important in the response to high-temperature stimuli. It is thus conceivable that, as illustrated in Fig. 2b, differential expression of these proteins are partially the consequence of the apparition of chalky tissue. Under 

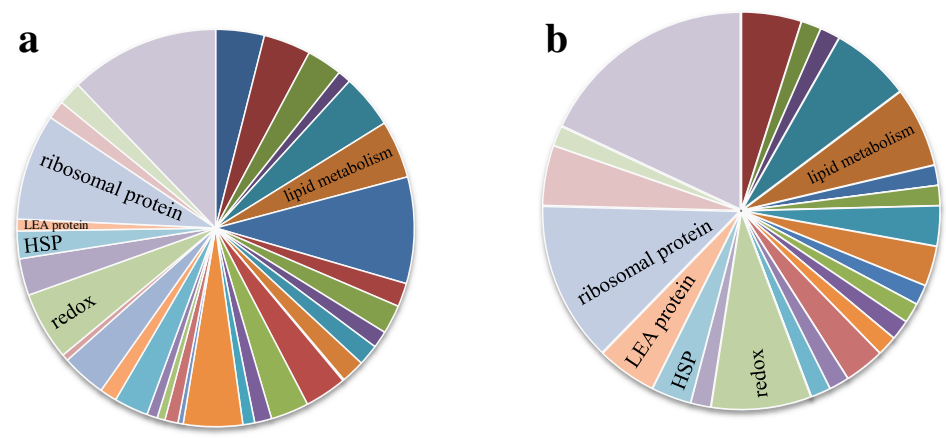

\begin{tabular}{|c|c|c|c|c|c|}
\hline $\begin{array}{l}\text { Total (A/B = 935/61) } \\
\text { - glycolysis }\end{array}$ & $(37 /-)$ & - carbohydrate metabolism & $(36 / 3)$ & citric acid cycle & $(45 / 1)$ \\
\hline - starch related & $(10 / 1)$ & - protein metabolism & $(41 / 4)$ & - lipid metabolism & $(44 / 4)$ \\
\hline - amino acid metabolism & $(81 / 1)$ & - nucleotide metabolism & $(18 /-)$ & - secondary metabolism & $(22 / 1)$ \\
\hline = ATP synthesis & $(13 /-)$ & - cell signaling & $(16 / 2)$ & membrane traffic & $(18 / 2)$ \\
\hline - cell cycle & $(1 / 1)$ & - kinase/phosphatase & $(32 /-)$ & expression regulation & $(29 / 1)$ \\
\hline - protein translocation & $(13 / 1)$ & - transporter & $(9 /-)$ & - protein folding & $(45 / 1)$ \\
\hline wormone & $(4 /-)$ & - inhibitor & $(10 / 2)$ & vATPase & $(6 /-)$ \\
\hline cytochrome & $(8 / 1)$ & cell wall & $(26 / 1)$ & cell skeleton & $(13 /-)$ \\
\hline ubiquitin proteasome & $(34 /-)$ & glyoxalase system & $(5 /-)$ & redox & $(52 / 5)$ \\
\hline stress related & $(28 / 1)$ & weat shock protein & $(21 / 2)$ & LEA protein & $(9 / 3)$ \\
\hline ribosomal protein & $(81 / 8)$ & nuclear protein & $(14 / 3)$ & storage protein & $(18 / 1)$ \\
\hline unknown & $(114 /$ & & & & \\
\hline
\end{tabular}

Fig. 2 Proteome of perfect and chalky grains of rice. Center part of perfect grains and opaque part of chalky grains harvested in 2009 and 2010 were subjected to protein extraction, followed by in solution shotgun proteomic analysis with iTRAQ labeling. (A/B): $\mathbf{a}$, Total identified proteins (935); $\mathbf{b} \geqq$ Two-fold up- or down-regulated proteins in the chalky grains of 2010 (61)

high-temperature stress, reactive oxygen species are generated, and cell membrane integrity is often lost leading to cell death. The heat-stressed plants signal for reprogramming cellular metabolism, either by increasing or decreasing the transcriptional and translational events. As shown in Fig. 3, we classified the detected stress-related proteins involved in oCG during 2009 and 2010 into four major groups according to their physiological functions: late embryogenesis abundant (LEA) (Fig. 3a), heat shock protein (HSP) (Fig. 3b), glutathione redox regulation (Fig. 3c) and other stress-related proteins (Fig. 3d).

The results suggested that in both oCG of 2009 and 2010 LEA proteins were markedly accumulated, being more abundant in oCG 2010 hot season $\left(+\sim 4{ }^{\circ} \mathrm{C}\right.$ than 2009). In oCG 2010, Q75LD9, Q8S7U3, like other six identified LEA proteins, increased in abundance, while Q9AWZ5 slightly decreased in abundance The majority of LEA proteins display a preponderance of hydrophilic and charged amino acid residues (Xiao et al. 2007). Also, considerable evidence suggests that LEA proteins are involved in desiccation resistance (Ingram and Bartels 1996), a variety of mechanisms for achieving this end have been proposed including protecting cellular structures from the effects of water loss by retention of water, sequestration of ions, direct protection of other proteins or membranes, or renaturation of unfolded proteins (Cuming 1999; Bray et al. 2000; Olvera-Carrillo et al. 2011).
HSPs can be used to stabilize protein conformation, prevent aggregation, and, therefore, maintain non-native proteins in a competent state for subsequent refolding in plants under heat stress (Morimoto 2002; Wang et al. 2004; $\mathrm{Zi}$ et al. 2013). The significant up-regulation of the HSPs is a key part of the heat shock response and is induced primarily by heat shock factors (HSFs) such as temperatures variability, drought, salinity, cold and chemicals (Scarpeci et al. 2008; Al-Whaibi 2011; Liao et al. 2013). Among the HSPs illustrated in this study, the amount of the HSP $81-1$, HSP $81-3$, and $70 \mathrm{kDa}$ HSP involved strong up-regulated in oCG 2010 -hot season-, while they were down-regulated in oCG 2009 -moderate temperature season-. The HSP70 family, group of molecular chaperones, such as BiP1 and BiP2 maintains polypeptides in an unfolded state (Lin et al. 2014). There is evidence that changes in BiP protein levels induce endoplasmic reticulum stress, and BiP overexpression affects the accumulation of seed storage proteins and, then, results in an opaque phenotype in the whole endosperm of rice (Yasuda et al. 2009). In addition, small heat-shock protein (sHSPs) encoding genes (HSP16.9A, HSP17.9A, HSP18.1) were up-regulated in oCG 2010, although the oCG 2009 moderately accumulated these sHSP (Fig. 3b). Among the various plant Hsps (i.e. HSP100, HSP90, HSP70, and HSP20), sHSPs have been identified to expressed in maximal amounts under high-temperature stress. They are also 

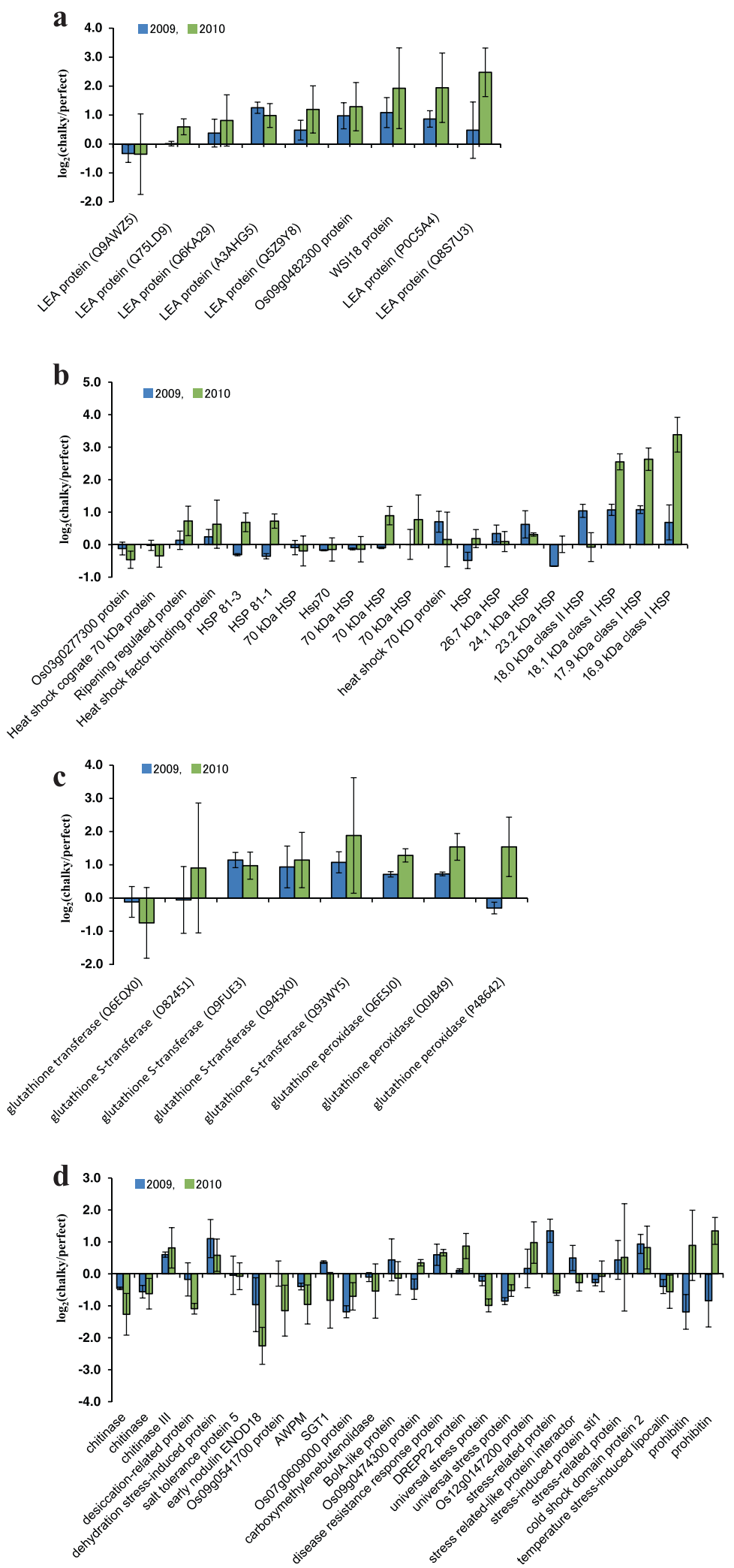

Fig. 3 (See legend on next page.) 
(See figure on previous page.)

Fig. 3 Proteome of stress-related proteins in chalky grains. Center part of perfect grains and opaque part of chalky grains harvested in 2009 and 2010 were subjected to protein extraction, followed by in solution shotgun proteomic analysis with iTRAQ labeling. a Late embryogenesis abundant proteins; $\mathbf{b}$ Heat shock proteins; $\mathbf{c}$ Glutathione redox regulation; $\mathbf{d}$ other stress-related proteins. Proteins were categorized by NCBI databases.

Values are represented as mean \pm s.d. $(n=3)$

up-regulated in rice caryopses during the grain milky stage (Lin et al. 2005; Liao et al. 2013). Our data were supported by a number of previous studies. HSP70 was reported to potentially be involved in a repair function after desiccation rather than biochemical stabilization in the dry state for Richtersius coronifer (Zi et al. 2013), whereas sHSPs associate with nuclei, cytoskeleton, and membranes, and as molecular chaperones they bind partially denatured proteins, thereby preventing irreversible protein aggregation during stress. sHSPs were positively correlated with the appearance of chalky kernels (Lin et al. 2005). In corroboration with another report (Das et al. 2015), the present results support the view that the induction of sHSPs suggests their function in re-establishing normal protein confirmation and thus cellular homeostasis. Besides, this study revealed that the high temperature in $2010\left(+\sim 4{ }^{\circ} \mathrm{C}\right)$ increased the abundance of high molecular weight HSPs. The HSP81.3 and 81.1, of the HSP90 gene family, are associated with different polypeptides serving a general mode of cellular activities. Moreover, the expression of the HSP90 genes and mRNA accumulation in plants and calli were strongly induced by high temperature (Milioni and Hatzopoulos 1997). HSP data indicate that the HSP90 (HSP81-1, HSP81-3) and $70 \mathrm{kDa}$ HSP may play an important role at the chalky tissue formation. It is believed that this diversification of HSP reflects an adaptation to tolerate the heat stress in chalky rice grains. Moreover, the physiological role of chaperones like HSP90 in plants remains poorly understood. Needless to say, further research will be necessary to study the possible positive correlation between the encoding proteins of high molecular HSPs and chalky endosperm.

As to the possible mechanisms explaining the high content of chalky grains in 2010, it is worth to note that the levels of some glutathione redox isoforms in oCG 2010 were, all of them, higher than oCG 2009 (Fig. 3c). Glutathione, implicated in the antioxidant defense through the ascorbate/GSH cycle, plays a key role in maintaining the homeostasis of reactive oxygen species (ROS). Glutathione S-transferases (GSTs) are ubiquitous enzymes encoded by a large family of genes, which play an important role in cellular detoxification to a wide variety of endobiotic and xenobiotic substrates by conjugating the tripeptide glutathione. GSTs have been found to be differentially regulated by dehydration (Bianchi et al. 2002). However, antioxidant systems cannot completely prevent the deleterious effects of ROS. In this study, nine of the identified proteins are implicated in redox homeostasis-related functions in chalky grains, including glutathione transferase
(GT), GSTs and glutathione peroxidase (GPX). Therefore, this would indicate that the ROS scavenging system may be activated in rice chalky kernels to alleviate such oxidative damage and to enhance high-temperature tolerance, mostly in 2010. Two proteins, GPX and GST, which are involved in the glutathione-ascorbate cycle for removing $\mathrm{H}_{2} \mathrm{O}_{2}$, showed the same expression patterns (Figs. 3c). GST and GPX can reduce $\mathrm{H}_{2} \mathrm{O}_{2}$ to its corresponding hydroxyl compounds to remediate oxidative membrane damage, and their expression showed the increases in abundance in chalky tissues. Some of these proteins were consistent with those observed in the rice (Lin et al. 2014) and maize (Luo et al. 2010) in response to stress in developing kernel tissues. Thus, our results, in conjunction with those previously reported (Liu et al. 2010; 2011; Lin et al. 2014), show that the up-regulation of these proteins, more pronounced in high-temperature conditions, suggest a close relation between redox homeostasis and the enhancement of chalky grains frequency. Recent investigation revealed that a heat-tolerant cultivar of rice exhibits a characteristic high expression of superoxide dismutase MSD1. In addition, the grain quality of transgenic overexpressor plants with the maize Ubiquitin-1 promoter fused to MSD1 was significantly improved in comparison with the wild type under heat stress after heading (Shiraya et al. 2015). We infer that the timely enhancement of $\mathrm{H}_{2} \mathrm{O}_{2}$ level by MSD1 under high-temperature stress is probably important, which acts as a signal that rapidly can promote the expression of stress-response proteins (Shiraya et al. 2015; Mitsui et al. 2016).

Among various additional chalky grain stress-related proteins, the expression of prohibitin and DREPP2 proteins were most remarkably increased under a high temperature -oCG 2010- (Fig. 3d). Moreover, a characteristic behavior of expression of prohibitin which may have multiple functions including mitochondrial chaperone activity (Tatsuta et al. 2005; Van Aken et al. 2009) was up-regulated in oCG 2010, while it was down-regulated under oCG 2009. To our knowledge, this study is the first to provide insights into the differential expression of prohibitin proteins in opaque chalky part collected from rice grains following heat stress season. Prohibitin have been shown to play central roles in cell cycle regulation, receptor-mediated signaling at the cell surface, aging, apoptosis, and plant development and senescence (Berger and Yaffe 1998; Coates et al. 1997; McClung et al. 1992, 1995; Nijtmans et al. 2002; Piper et al. 2002; Chen et al. 2005). Recent studies using muscovy ducks suggested changes in the abundance of the mitochondrial 
protein chaperone, prohibitin, into thermal tolerance related to energy metabolism (Zeng et al. 2013).

The biosynthesis of starch is the major determinant of yield in cereal grains (Emes et al. 2003). Furthermore, the main constituent of the rice grain is starch, thus the grain filling capacity is determined mainly by the starchsynthesizing capability of endosperm. Proteins associated with carbohydrate metabolism, especially starch synthesis, showed altered expression patterns induced by high temperature. Among them, the $\alpha$-amylase isoform, Amy3E (AmyII-3), was dramatically up-regulated in oCG 2010 (Fig. 4a). As expected, the expression level of granule-bound starch synthase 1 (GBSS1), starch branching enzyme (SBE) BEIIb, soluble starch synthases (SS), and sucrose synthases (SuSy) were down-regulated in the chalky grains (Fig. 4a, b). It has been observed that the expression of starch-synthesis-related genes repressed under high-temperature conditions (Yamakawa et al. 2007). In the growing rice grains, the concerted functioning of multiple forms of granule-bound (GBSS) and SS, SBE and debranching enzymes (DBE), together with the ADPG supplying strength, determine the overall grain- filling capacity ( $\mathrm{Su} 2000$ ). Thus, the impaired balance of starch biosynthesis and degradation at oCG 2010 may increase the rate of grains to appear chalky because of the imperfect filling of endosperm cells with starch granules.

Noteworthy, high-temperature stress can lead to changes in the other proteins involved in lipid (Fig. 2b, Additional file 1: Table S1) and glycolysis metabolic processes (Fig. 2b), suggesting that primary metabolism might have been inhibited in chalky grains. Indeed, we found the lipid metabolism-related proteins, caleosin and sterol carrier protein, were differentially expressed in oCG, which may aid the mechanisms of chalkiness formation. The down-regulation of these proteins might retard the metabolic speed of fatty acid synthesis, under hightemperature conditions, in chalky grains. Because caleosin is associated with the endoplasmic reticulum and/or oil bodies (OBs) in seed embryo development (Næsted et al. 2000), promotes specific interaction of OBs with vacuoles and facilitates access to triacylglycerides, to serve as energy source, by lipases (Poxleitner et al. 2006). Likewise, sterol carrier protein, peroxisomal lipid protein, might affect the transfer of lipids between membranes, $\beta$ -

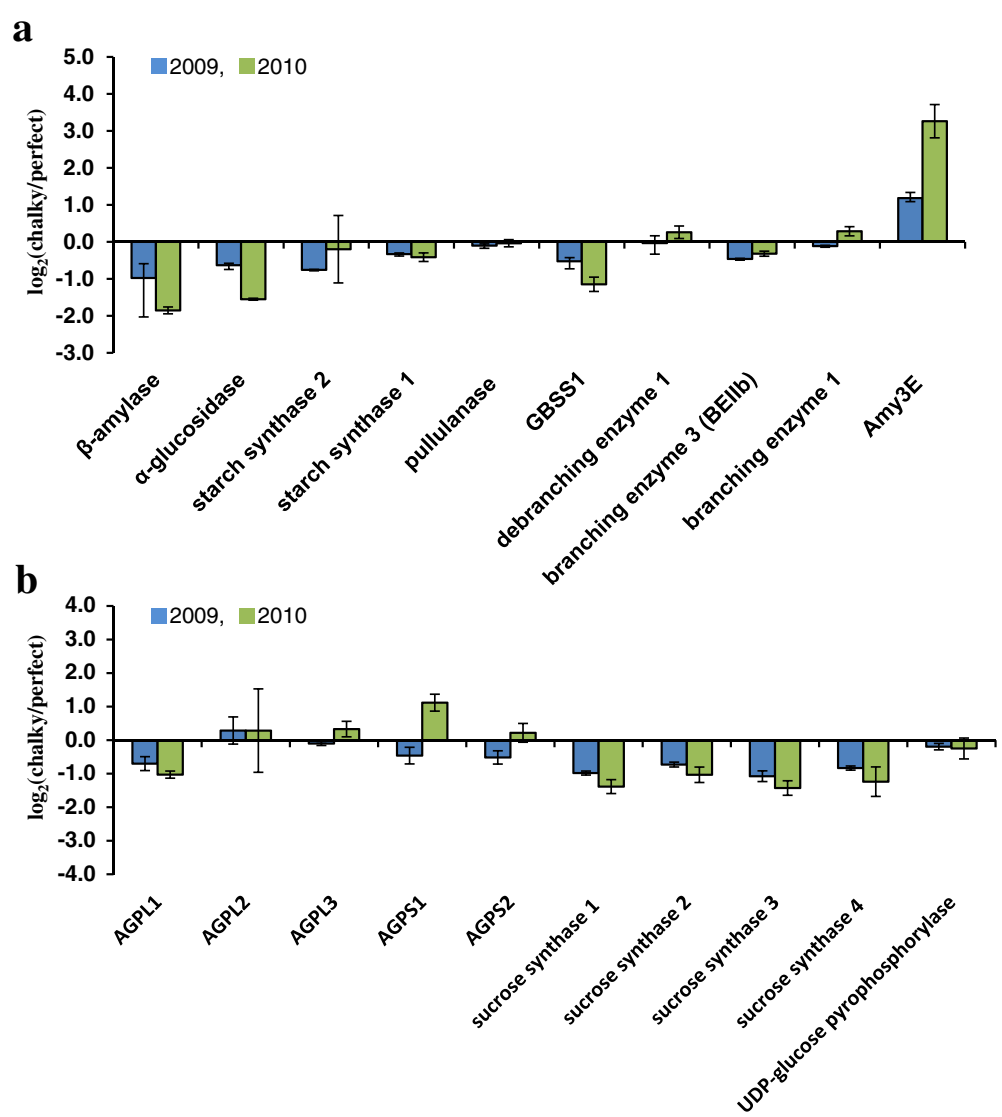

Fig. 4 Proteome of starch metabolism in chalky grains. Center part of perfect grains and opaque part of chalky grains harvested in 2009 and 2010 were subjected to protein extraction, followed by in solution shotgun proteomic analysis with iTRAQ labeling. a starch synthesis and degradation; b ADP-glucose supply. Values are represented as mean \pm s.d. $(n=3)$ 
oxidation and glyoxylate pathways, and hence the normal development and morphology of grains (Zheng et al. 2008). Thus, down-regulation of lipid metabolism related proteins probably contribute to the chalkiness formation in grains of 2009-to-2010. Further detailed investigations, including lipid profiling may provide us with additional clues to the biological function of those proteins in chalkiness formation.

\section{Glycomic characteristics of chalky grains caused under different temperature conditions}

Starch quality is an important parameter in determining the quality of rice grains. Numerous investigations have revealed that the environmental temperature at the grain filling stage apparently alters the starch composition in rice grains (Mitsui et al. 2016). Furthermore, the content and fine structure of amylose and amylopectin in starch affect the physicochemical characteristics (such as viscosity) and texture properties of the rice grains (Muench et al. 1997). We have previously determined amylose contents and chain-length distributions of starches prepared from the translucent and opaque parts of perfect and chalky grains of Koshihikari harvested in 2009 and 2010 using a fluorescence labeling followed by HPLC sizeexclusion chromatography. These data have suggested that the contents of amylose chain-length distributions between the translucent and opaque parts of rice grains in both seasons were similar. Although, slight differences in the contents of amylose and long B chains of amylopectin were observed in 2009 and 2010 (Tsutsui et al. 2013). To confirm the results, we conducted a further analysis of chain-length distribution of amylopectin of PG 2009, tCG 2009, oCG 2009, PG 2010, tCG 2010, and oCG 2010 using the fluorescence capillary electrophoresis (FCEP) method. As shown in Fig. 5, these analyzes revealed clearly that the differences in the chain-length distribution of starch among the perfect grains and the translucent and opaque parts of chalky grains were below the detection limit. In oCG and tCG 2010, the relative amounts of amylopectin middle-size chains (DP20-30) slightly increased while short-chain DP5-15 decreased, although no differences between two parts in the same chalky grains were observed (Fig. 5). Therefore, the reason for the appearance of loosely-packed round-shaped starch granules of the chalky grains must be attributed to factors other than chain-length distribution of amylopectin.

High-temperature stress decreased the amylose contents and the weight ratio of $\mathrm{A}+$ short $\mathrm{B}$ chains to long B chains of amylopectin (Asaoka et al. 1984; Inouchi et al. 2000). In line with these conclusions, previous results of our group obtained by analyzing the starch composition of Koshihikari grains harvested in moderate and high-temperature conditions were not contradictory to the conclusions mentioned above (Tsutsui et al. 2013).
Furthermore, transcriptomic analysis of developing rice seeds has demonstrated that the expression of several starch synthesis-related genes including GBSSI, BEIIb, ADP-glucose pyrophosphorylase (AGPS2b, AGPS1 and $A G P L 2)$ and ADP-glucose translocator (BT1-2) were decreased under high-temperature condition (Yamakawa et al. 2007). It is well known that the amylose-extender (ae) mutant of rice, that is deficient in BEIIb gene, exhibited a severe chalky phenotype of grain. The ae mutant revealed that the mutation in the gene for BEIIb specifically altered the structure of amylopectin in the endosperm by reducing short chains with degree of polymerization of 17 or less, with the greatest decrease in chains with degree of polymerization of 8 to 12 and enriched in long chains with DP more than 19 (Nishi et al. 2001). The chalkiness of ae mutant was alleviated by manipulation of BEIIb activity (Tanaka et al. 2004; Abe et al. 2014), suggesting that the unusual expression of BEIIb could be one of the key factors causing the grain chalkiness. However, Yamakawa et al. (2007) showed that the reduction of amylase content and amylopectin side chain by high temperature was not correlated to the grain chalkiness in rice cultivars ranging from high-temperature tolerance to high temperature sensitive. Thus, the relevance of the starch fine structure to the chalkiness of grain under hightemperature stress is obscure.

The function of starch synthesis-degradation in stem seems to serve as an important regulatory role of rice grain filling. The starch synthesis in grains starts from sucrose translocated from leaf cells. The contents of soluble starch in the opaque parts (oCG 2009 and oCG 2010) were remarkably high in comparison with the corresponding translucent parts of perfect grains (PG 2009 and PG 2010) (Fig. 6a), indicating that amylolytic enzyme exists and works in the opaque parts of chalky grains. Soluble sugar contents including sucrose were significantly increased in oCG 2010 (Fig. 6b). The sucrose contents of oCG under high temperature were higher than PG and those in 2009. It is thus likely that the downregulation of SuSy proteins under heat stress is one reason for the accumulation of sucrose in chalky grains. Another striking alteration involving downregulation of the sucrose transporter (OsSUT1) under heat stress favored the accumulation of sucrose in these organs (Phan et al. 2013). Another possible reason explaining the accumulation of sucrose is to alleviate water stress as a consequence of osmotic adjustment. Recent findings during rice grain filling, under simultaneous occurrence of high temperature and water deficit, showed that sugars to be synthesized to starch kept accumulating in vacuoles and cytosol in the cells (Wada et al. 2014), so that the cells could be expanded by maintaining water volume in size and cell $\Psi \mathrm{p}$ (Morgan 1977; Meyer and Boyer 1981), followed by starch accumulation. 

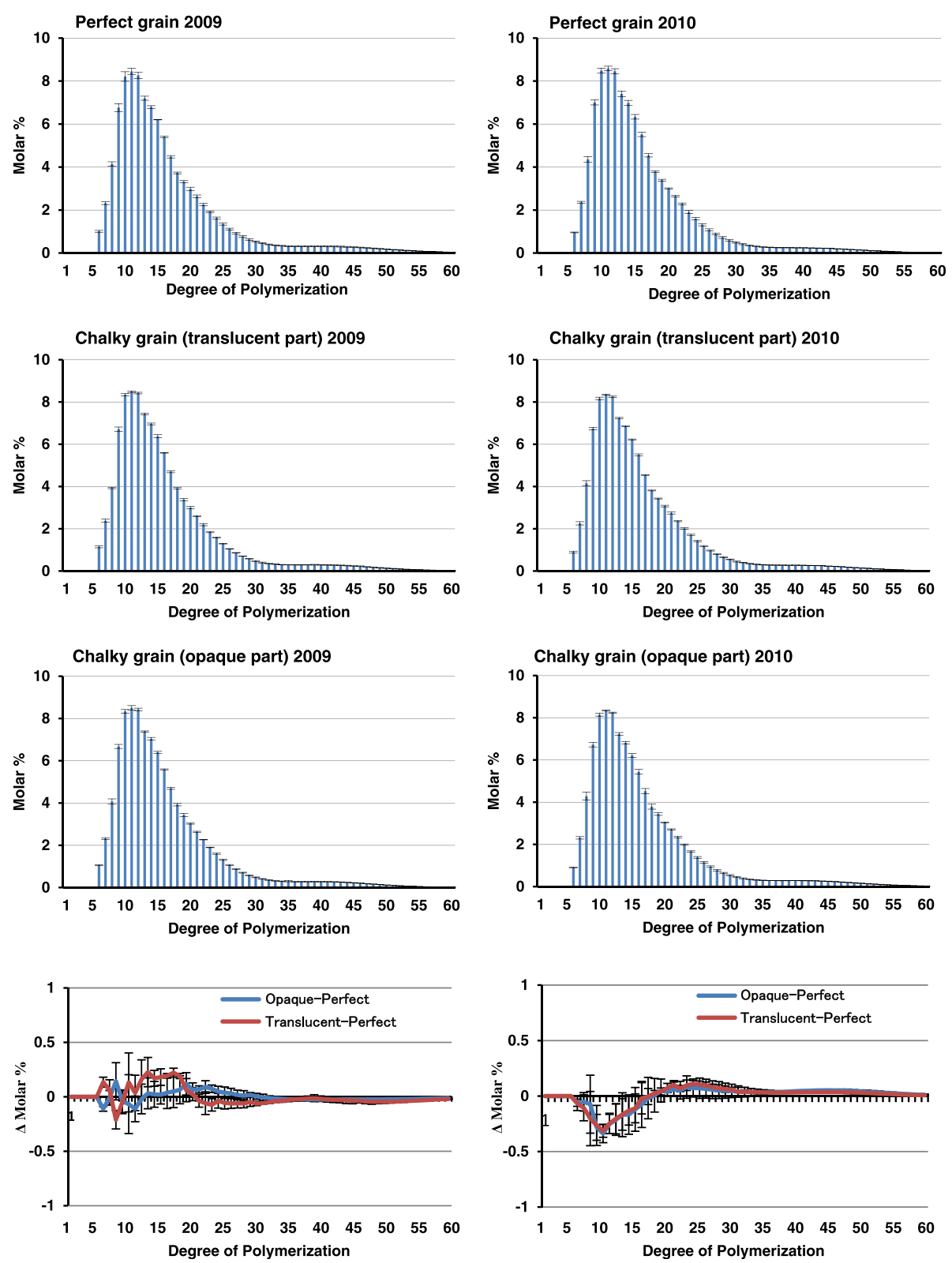

Fig. 5 Chain-length distributions of perfect and chalky grain amylopectins of rice. Rice grains were harvested in 2009 and 2010 that the average temperatures of grain filling periods were 24.4 and $28.0^{\circ} \mathrm{C}$, respectively. Center part of perfect grains and translucent and opaque parts of chalky grains were subjected to starch extraction, followed by APTS labeling and capillary electrophoretic analysis. Bottom panels show differences in the chain distributions of amylopectins in perfect and chalky grains. Blue lines, differences between the opaque part of chalky grain and perfect grain; red lines, differences between the translucent part of chalky grain and perfect grain. Values are represented as mean \pm s.d. $(n=3)$

We further determined the amounts of $\alpha$-amylase isoforms in PG 2009, oCG 2009, PG 2010, and oCG 2010 by Western blotting (Fig. 7a, b). The results showed that AmyII-3 (Amy3E) and AmyII-4 (Amy3D) were highly expressed in oCG 2010 compared with PG 2010, and AmyI-1 (Amy1A) and AmyII-4 were significantly expressed in oCG 2009 compared with PG 2009 (Fig. 7b). It is noteworthy that in developing seeds of rice, the expression of $\alpha$-amylase genes Amy1A, Amy1C, Amy3D and
$A m y 3 E$ were induced under high-temperature stress and its suppression, through RNA interference (RNAi) strategy, ameliorated rice grain damage such as chalkiness (Hakata et al. 2012). Asatsuma et al. (2005) reported that ectopic overexpression of $\alpha$-amylases such as Amy1A and Amy3D produced chalky grains even under ambient temperature. As the extent of the decrease in chalky grains was highly correlated to decreases in the expression of Amy1A, Amy1C, Amy3A and Amy3B. Furthermore, studies have 


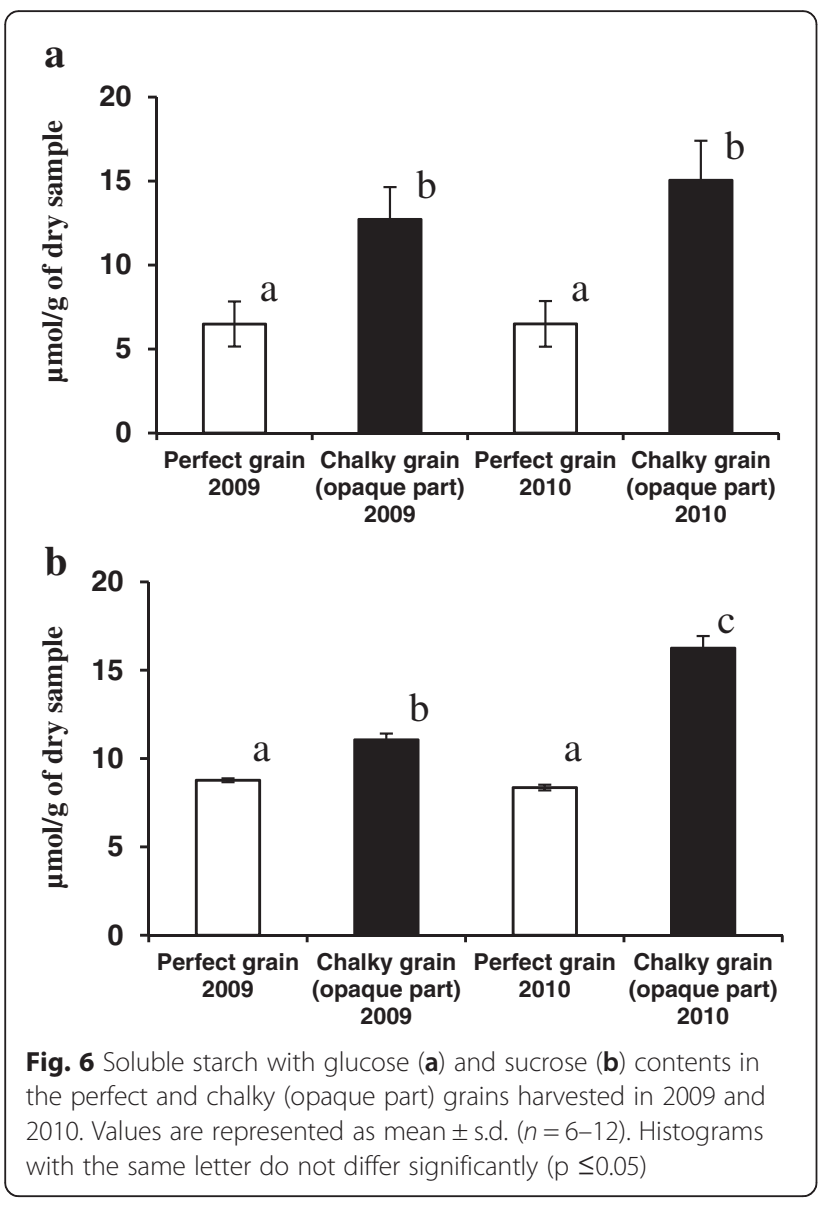

demonstrated that AmyI-1 and AmyII-4 proteins existed in the outer layers (100 to $80 \%$ fractions) of rice grain (cv. Koshihikari), while $\alpha$-glucosidase and AmyII-3 were mainly detected in the inner layers (80 to $0 \%$ fractions) by immunoblotting with the specific antibodies. Likewise, starchcomponent profiles are impacted by changes in air temperature. The overall experimental results revealed that the degradation of starch accumulating in the developing grains by amylase under high temperature is an another layer of regulation causing the chalkiness.

\section{Conclusions}

In this study, the higher coverage of rice grains proteome by the iTRAQ/Shotgun strategy offered a good opportunity to discover more stress-related proteins involved in chalkiness tissue. Under field conditions, the differentially expressed proteins in opaque chalky grains under moderate (2009) and heat stress (2010) suggest three highly enriched functional terms, i.e. LEA proteins, HSPs, and glutathione peroxidase and S-transferase. These analyzes give us a better understanding about the chalky dynamics with global-mean warming of roughly $4{ }^{\circ} \mathrm{C}$ in rice grains. Furthermore, the formation of chalky grain under hightemperature season is also triggered by alterations in proteins associated with carbohydrate metabolism and starch structure. Thus, down-regulation of genes involved in starch biosynthesis and the involvement of $\alpha$-amylase isoforms in the central opaque area of chalky grains were elucidated under elevated temperature. Our results provide new insights into proteome and glycome characterization in perfect and chalky grain in high-temperature scenarios at the field. The proteins identified here provide a basis to elucidate further the molecular mechanisms underlying the chalkiness under elevated temperature and may reveal useful targets in climate change scenarios studies and strategies.

\section{Methods}

Plant materials

Rice grains (Oryza sativa L. cv. Koshihikari) grown at Sanjo city (Niigata, Japan) were harvested in two consecutive years, 2009 and 2010. The average temperatures during the heading and ripening period of Koshihikari in the area of 2009 and 2010 were 24.4 and $28.0^{\circ} \mathrm{C}$, respectively. Grain quality (chalky or perfect) was determined with a rice grain grader (RGQI20A, Satake, Hiroshima, Japan). "Perfect" grains (PG) that exhibited a transparency and "chalky" grains (tCG) that contain opaque part(s) (oCG) within the endosperm were selected from these harvested grains on a viewer (Fujicolor light box New-5,000 Inverter, Fuji film Co., Tokyo, Japan). All the samples were stored in a temperature range of 4 to $10{ }^{\circ} \mathrm{C}$ until the experiment was carried out.

\section{Scanning electron microscopy (SEM)}

Brown rice grain was cracked with a razor blade, and the cracked surface was coated with gold for $90 \mathrm{~s}$ using a vaporizer (IB-3, EIKO, Tokyo, Japan) and subjected to a Scanning Electron Microscope (JSM6510LA, JEOL, Tokyo, Japan). Observation conditions were as follows: acceleration voltage, $10 \mathrm{kV}$; magnification, 1,000-10,000. SEM analysis was run using three biological replicates with at least four technical repetitions of developing grains per replication of the mounted specimens.

\section{Proteomic analysis}

Two hundred mg of starchy endosperm prepared from the opaque part of chalky grains or the corresponding part of perfect grains were ground in liquid nitrogen to fine powder and then suspended in $7 \mathrm{M}$ urea, $2 \mathrm{M}$ thiourea, $3 \%$ (w/ v) CHAPS, $1 \%(\mathrm{v} / \mathrm{v})$ Triton X-100, and $10 \mathrm{mM}$ DTT. The suspensions were centrifuged at $10,000 \times g$ at $4{ }^{\circ} \mathrm{C}$ for $5 \mathrm{~min}$. The supernatants were mixed with $1 / 10$ volume of $100 \%(\mathrm{w} / \mathrm{v})$ trichloroacetic acid, incubated on ice for $15 \mathrm{~min}$, and centrifuged at $10,000 \times g$ at $4{ }^{\circ} \mathrm{C}$ for $15 \mathrm{~min}$. The resulting protein precipitates were washed 3 times in ice-cold acetone and resuspended in $8 \mathrm{M}$ urea. Protein concentration was determined by the Pierce $660 \mathrm{~nm}$ Protein 

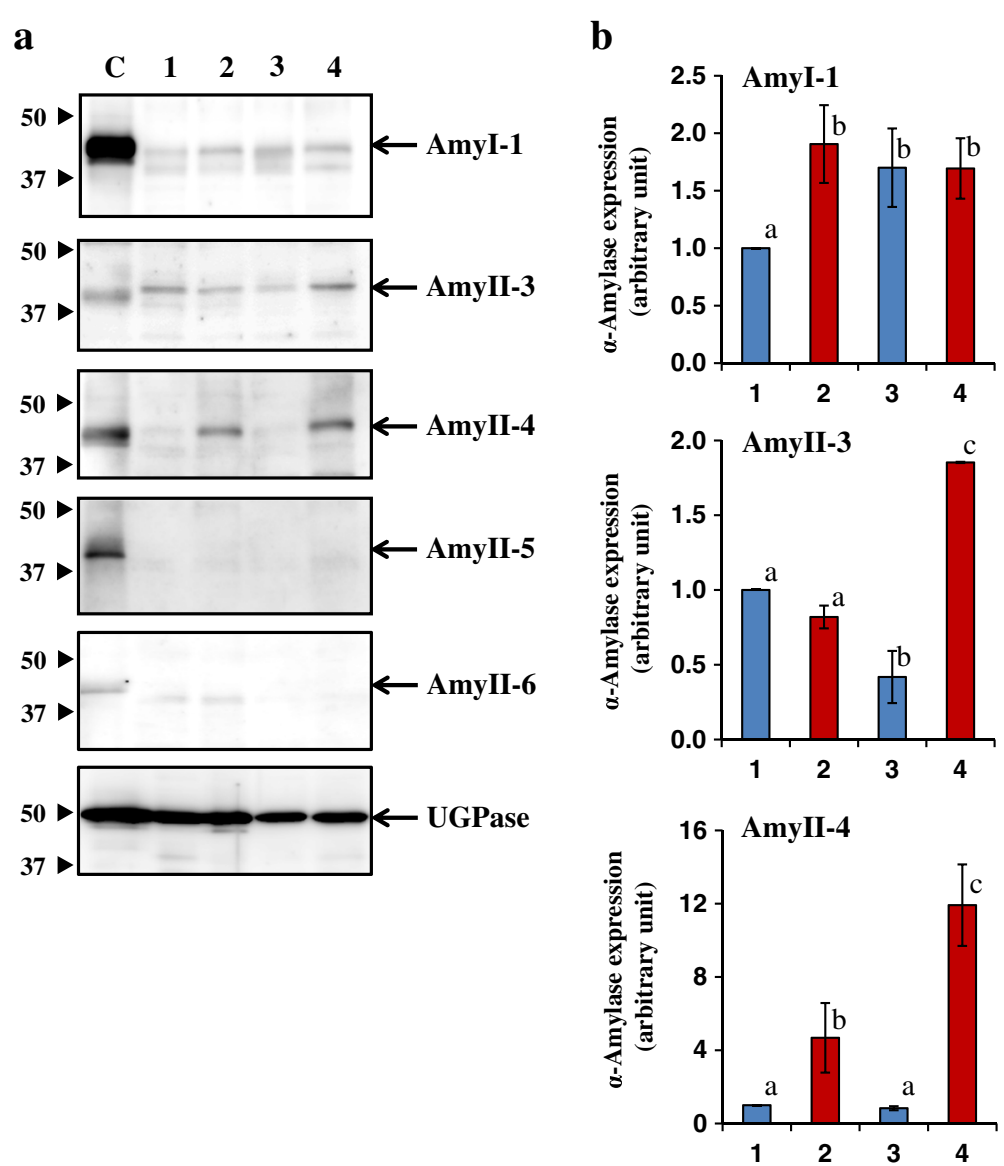

Fig. 7 Changes in the expression of a-amylase isoforms in central opaque area of chalky grains harvested in 2009 and 2010. a Immunoblotting images. Center part of perfect grain and opaque part of chalky grain were subjected to protein, followed by SDS-PAGE and immunoblotting with specific antibodies. C, germinating seeds after 5 days of imbibition; lane 1, perfect grain in 2009; lane 2, chalky grain in 2009; lane 3, perfect grain in 2010; lane 4, chalky grain in 2010. b Quantitation of a-amylase isoforms expression. Amount of each a-amylase isoform in perfect grains was normalized to 1 unit. The perfect proteins of Amyll-5 and Amyll- 6 were not detected. Values are represented as mean \pm s.d. $(n=3)$. Histograms with the same letter do not differ significantly $(p \leq 0.05)$

Assay Kit (Thermo Fisher Scientific) using bovine serum albumin (BSA) as a standard.

The procedure of quantitative shotgun proteomic analysis was essentially identical as described previously (Shiraya et al. 2015). Each protein preparation $(50 \mu \mathrm{g})$ was digested in $20 \mu \mathrm{l}$ of endoproteinase Lys-C $\left(1 \mu \mathrm{g} \mu \mathrm{l}^{-1}\right)$ at $37^{\circ} \mathrm{C}$ for $3 \mathrm{~h}$, then diluted to 10 times volume by ultrapure water $(18.2 \mathrm{M} \Omega \mathrm{cm})$. The diluted samples were further digested in $200 \mu \mathrm{l}$ of trypsin $\left(1 \mu \mathrm{g} \mu \mathrm{l}^{-1}\right)$ at $37{ }^{\circ} \mathrm{C}$ for $12 \mathrm{~h}$. iTRAQ labeling of peptides were carried out with 4-plex iTRAQ tags the manufacturer's protocol (Sciex), and the resultant 4 iTRAQ-labeled peptide samples were mixed. ITRAQ analysis was performed by using a DiNa-A-LTQOrbitrap-XL system. The iTRAQ labeled peptides were loaded on a trap column (HiQ sil C-18 W-3; 0.5 mm i.d. $\times$ $1 \mathrm{~mm}, 3 \mu \mathrm{m}$ particle size) with buffer A consisting of $0.1 \%(\mathrm{v} / \mathrm{v})$ formic acid and $2 \%(\mathrm{v} / \mathrm{v})$ acetonitrile in water using a DiNa-A system (KYA Tech., Tokyo, Japan). A linear gradient from 0 to $33 \%$ buffer B $(0.1 \%$ formic acid and $80 \%$ acetonitrile in water) for $600 \mathrm{~min}, 33$ to $100 \% \mathrm{~B}$ for $10 \mathrm{~min}$ and back to $0 \% \mathrm{~B}$ in $15 \mathrm{~min}$ was applied, and peptides eluted from the HiQ sil C-18 W-3 column were directly loaded on a separation column (MonoCap C18 High Resolution 2000; 0.1 mm i.d. x 2000 mm, $2 \mu \mathrm{m}$ pore size). The separated peptides were introduced into an LTQ-Orbitrap XL mass spectrometer (Thermo Fisher Scientific) with a flow rate of $300 \mathrm{~nL} \mathrm{~min}{ }^{-1}$ and an ionization voltage $1.7-2.5 \mathrm{kV}$.

Liquid chromatography-MS/MS (LC-MS/MS) spectrometer was operated using Xcalibur 2.0 software (Thermo Fisher Scientific). The mass range selected for MS scan was set to $350-1,600 \mathrm{~m} / \mathrm{z}$ and the top three peaks were subjected to MS/MS analysis. Full MS scan was detected in the Orbitrap, and the MS/MS scans were detected in the linear ion trap and Orbitrap. The normalized collision energy for MS/MS was set to $35 \mathrm{eV}$ for collision-induced dissociation (CID) and $45 \mathrm{eV}$ for higher-energy C-trap dissociation (HCD). High resolution of Fourier transform 
mass spectrometer (FTMS) was maintained at 60,000 resolution. Divalent or trivalent ions were subjected to MS/ MS analysis in dynamic exclusion mode, and proteins were identified with Proteome Discoverer v. 1.4 software and the SEQUEST HT (Thermo Fisher Scientific) and MsAmanda (Dorfer et al. 2014) search tool using the UniProt (http:// www.uniprot.org/) $O$. sativa subsp. japonica database (63,535 proteins) with the following parameters: enzyme, trypsin; maximum missed cleavages site, 2; peptide charge, $2+$ or $3+$; MS tolerance, 5 ppm; MS/MS tolerance, $\pm 0.5 \mathrm{Da}$; dynamic modification, carboxymethylation (C), oxidation (H, M, W), iTRAQ 4-plex (K, Y, N-terminus). False discovery rates were $<1 \%$.

\section{Western blotting}

The starchy endosperm samples (500 mg) were powdered in liquid nitrogen and suspended in $1 \mathrm{~mL}$ of $10 \mathrm{mM}$ Tris$\mathrm{HCl}(\mathrm{pH} 7.5), 1.0 \mathrm{mM} \mathrm{CaCl}_{2}$ and $0.1 \%(\mathrm{w} / \mathrm{v})$ Triton X100 for $15 \mathrm{~h}$ at $4{ }^{\circ} \mathrm{C}$. The suspension was centrifuged at 15 $000 \times g$ for $10 \mathrm{~min}$ at $4{ }^{\circ} \mathrm{C}$. An aliquot of the supernatant was subjected to sodium dodecyl sulfate - polyacrylamide gel electrophoresis (SDS-PAGE) in $12 \%$ separation gels. After electrophoresis, the separated proteins were transferred to polyvinylidene fluoride membranes (Hybond-P; GE Healthcare, USA). The membranes were incubated in $15 \mathrm{mM}$ phosphate-buffered saline $(\mathrm{pH}$ 6.8) containing $0.1 \%$ Tween-20 and $5 \%$ skim milk for blocking, and then reacted with specific antibodies: anti-rice $\alpha$-amylase isoform AmyI-1 (rabbit serum; 1:10,000), AmyII-3 (mouse serum; 1:500), AmyII-4 (rabbit serum; 1:5,000) (Itayagoshi et al. 2015), AmyII-5, AmyII-6 (rabbit serum; 1:5000) (Nanjo et al. 2004) and UDPglucose pyrophosphorylase (Nanjo et al. 2004). Horseradish peroxidase-conjugated anti-rabbit IgG (Nacalai Tesque, Japan) and anti-mouse IgG (MP Biomedicals, USA) were used as secondary antibodies. The $\alpha$-amylase immunobloting assay is isoforms specific, as there is no cross-reactivity of the test among isoforms AmyI-1, Amy II-4 (Mitsui et al. 1996) and Amy II-3 (Tsuyukubo et al. 2012), due to antibody specificity used in the test. The immunoreactive bands were visualized using chemiluminescence reagent (Amersham, UK), and quantified by LAS-3000 molecular imager (Fujifilm, Japan) (Asatsuma et al. 2005).

\section{Measurement of chain-length distribution of starch}

The method determining chain-length distribution of starch was essentially identical to the procedure described by Fujita et al. (2012). Starchy endosperm ( $5 \mathrm{mg}$ ) was ground with a mortar and pestle and the powder was boiled in $1.5 \mathrm{ml}$ of methanol for $10 \mathrm{~min}$. The suspension was centrifuged at 3,000 $\mathrm{x} g$ and room temperature for $5 \mathrm{~min}$. The pellet was re-suspended in $1.5 \mathrm{ml}$ of $90 \%(\mathrm{v} / \mathrm{v})$ methanol, and centrifuged at 3,000 $\mathrm{x} g$ for $5 \mathrm{~min}$ at room temperature. After removing methanol, the pellet was suspended with $143 \mu \mathrm{l}$ of ultrapure water, and mixed with $7.5 \mu \mathrm{l}$ of $5 \mathrm{~N} \mathrm{NaOH}$ and boiled for $5 \mathrm{~min}$. The $\alpha$-glucan sample was desalted and subjected to hydrolysis with isoamylase $(0.03 \mathrm{U} / \mathrm{mg}$ of amylopectin in $40 \mathrm{mM}$ acetate buffer, $\mathrm{pH} 4.4$ ) at $37^{\circ} \mathrm{C}$ for $12 \mathrm{~h}$. The chain length distributions of $\alpha$-glucans from endosperm were analyzed using the fluorescence capillary electrophoresis (FCEP) method of O'Shea and Morell (1996) in a P/ACE MDQ Carbohydrate System (Beckman Coulters, CA, USA).

\section{Soluble starch and sucrose contents}

Briefly, $50 \mathrm{mg}$ of starchy endosperm was treated with $2 \mathrm{ml}$ of $80 \%$ ethanol in boiling water bath for $1 \mathrm{~min}$, and the mixture was centrifuged at $10,000 \mathrm{x} g$ for $10 \mathrm{~min}$. The ethanol extraction was carried out three times. The ethanol fraction containing soluble glycan and free sugars was dried-up and then subjected to sugar assays. The soluble glycan was hydrolyzed by 5 unit of amyloglucosidase and 1 unit of $\alpha$-amylase, and the released glucose from soluble glycan was measured by a coupled enzyme reaction using hexokinase (HK) and Glc-6-P dehydrogenase (G6PDH) (Guglielminetti et al. 1995). The assay mixture, composed of $100 \mathrm{mM}$ Tris- $\mathrm{HCl}$ (pH 7.6), $3 \mathrm{mM} \mathrm{MgCl}, 2 \mathrm{mM}$ ATP, $0.6 \mathrm{mM} \mathrm{NAD}^{+}, 1$ unit of $\mathrm{HK}$ and 1 unit of G6PDH, was incubated at $37^{\circ} \mathrm{C}$ for $30 \mathrm{~min}$. After cooling, absorbance was measured at $340 \mathrm{~nm}$ using a spectrophotometer (Hitachi U-2900). Sucrose was first broken down using 85 units invertase (in $15 \mathrm{mM}$ sodium acetate, $\mathrm{pH} 4.6$ ) and the resulting glucose and fructose were assayed as described above.

\section{Additional file}

Additional file 1: Table S1. Proteomic comparison of chalky and perfect grains harvested in 2009 and 2010. s.d., standard deviation; \# AAs, the number of amino acids; MW, the calculated molecular weight; pl, the calculated isoelectric point; $\Sigma$ Coverage, the percentage of sequence coverage. (XLSX $62343 \mathrm{~kb}$ )

\section{Abbreviation}

ADPG, adenosine diphosphate D-glucose; AGP, ADPG pyrophosphorylase; AGPP, ADPG pyrophosphatase; Amy, amylase; BE, branching enzyme; DBE, debranching enzyme; G6PDH, Glc-6-P dehydrogenase; GBSS, granule bound starch synthase; GPX, glutathione peroxidase; GST, glutathione S-transferases; GT, glutathione transferase; HK, hexokinase; HSPs, heat shock proteins; LEA, late embryogenesis abundant; oCG, opaque chalky grain; PG, perfect grain; PPase, pyrophosphorylase; ROS, reactive oxygen species; SDS, sodium dodecyl sulfate; sHSPs, small HSPs; SPS, sucrose phosphate synthase; SS, starch synthase; SuSy, sucrose synthase; tCG, transparent chalky grain; UDPG, UDPglucose; UGPase, UDP-glucose pyrophosphorylase.

\section{Competing interests}

The authors declare that they have no competing interests. The authors declare that the research was conducted in the absence of any commercial or financial relationships that could be construed as a potential conflict of interest.

\section{Authors' contributions}

TM planned and supervised the project. KK and MS designed the experimental plot. KK, MS, NK, HS, YS, TI, and TS conducted the experiments. 
$\mathrm{KK}, \mathrm{MS}, \mathrm{Kl}$, and $\mathrm{MB}$ analyzed the data and interpreted the results. TM, MB, and KK wrote the paper. All authors read and approved the final manuscript.

\section{Acknowledgements}

This research was supported by KAKENHI Grants-in-Aid for Scientific Research (A) (15H02486) from Japan Society for the Promotion of Sciences and Grant for Promotion of KAAB Projects (Niigata University) by the Ministry of Education, Culture, Sports, Science, and Technology; Japan. We wish to thank Dr. T. Sawada (Akita Prefectural University) for analyzing chain-length distribution of starch, and Dr. K. Tsutsui (Aichi University of Education) for helpful discussion.

\section{Author details}

${ }^{1}$ Graduate School of Science and Technology, Niigata University, Niigata 950-2181, Japan. ${ }^{2}$ Department of Applied Biological Chemistry, Niigata University, Niigata 950-218, Japan. ${ }^{3}$ Present address: Niigata Crop Research Center, Niigata Agricultural Research Institute, Nagaoka 940-0826, Japan.

\section{Received: 15 February 2016 Accepted: 11 May 2016}

\section{Published online: 31 May 2016}

\section{References}

Abe N, Asai H, Yago H, Oitome NF, Itoh R, Crofts N, Nakamura Y, Fujita N (2014) Relationships between starch synthase I and branching enzyme isozymes determined using double mutant rice lines. BMC Plant Biol 14:80 doi:10.1186/1471-2229-14-80

Al-Whaibi MH (2011) Plant heat-shock proteins: A mini review. J King Saud Univ - Sci 23:139-150. doi:10.1016/j.jksus.2010.06.022

Asaoka M, Okuno K, Sugimoto Y, Kawakami J, Fuwa H (1984) Effect of environmental temperature during development of rice plants on some properties of endosperm starch. Starch/Stärke 36:189-193. doi:10.1002/star.19840360602

Asatsuma S, Sawada C, Itoh K, Okito M, Kitajima A, Mitsui T (2005) Involvement of a-amylase $1-1$ in starch degradation in rice chloroplasts. Plant Cell Physiol 46:858-869. doi:10.1093/pcp/pci091

Berger K, Yaffe M (1998) Prohibitin family members interact genetically with mitochondrial inheritance components in Saccharomyces cerevisiae. Mol Cell Biol 18:4043-4052. doi:10.1128/MCB.18.7.4043

Bianchi MW, Roux C, Vartanian N (2002) Drought regulation of GST8, encoding the Arabidopsis homologue of ParC/Nt107 glutathione transferase/ peroxidase. Physiol Plant 116:96-105. doi:10.1034/j.1399-3054.2002.1160112.x

Bray EA, Bailey-Serres J, Weretilnyk E (2000) Responses to abiotic stresses. In: Buchanan BB, Gruissem W, Jones RL (eds) Biochemistry and Molecular Biology of Plants. American Society of Plant Physiologists, Rockville, pp 1158-1203

Bressani R, Elias LG, Juliano BO (1971) Evaluation of the protein quality and milled rices differing in protein content. J Agric Food Chem 19:1028-1034

Chen JC, Jiang CZ, Reid MS (2005) Silencing a prohibitin alters plant development and senescence. Plant J 44:16-24. doi:10.1111/j.1365-313X.2005.02505.X

Cheng F, Zhong L, Zhao N, Liu Y, Zhang G (2005) Temperature induced changes in the starch components and biosynthetic enzymes of two rice varieties. Plant Growth Regul 46:87-95

Coates PJ, Jamieson DJ, Smart K, Prescott AR, Hall PA (1997) The prohibitin family of mitochondrial proteins regulate replicative lifespan. Curr Biol 7:607-610. doi:10.1016/S0960-9822(06)00261-2

Commuri PD, Jones RJ (1999) Ultrastructural characterization of maize (Zea mays L.) kernels exposed to high temperature during endosperm cell division. Plant Cell Environ 22:375-385. doi:10.1046/j.1365-3040.1999.00424.x

Cuming AC (1999) Lea proteins. In: Shewry PR, Casey R (eds). Seed Proteins. Kluwer Academic Publishers, Dordrecht, The Netherlands, pp 753-780

Das S, Krishnan P, Mishra V, Kumar R, Ramakrishnan B, Singh HK (2015) Proteomic changes in rice leaves grown under open field high temperature stress conditions. Mol Biol Rep 42:1545-1558. doi:10.1007/s11033-015-3923-5

Defeng Z, Shaokai M (1995) Rice production in China under current nd future climates. In: Malthews RB, Kropff MJ, Bachelet D, van Laar HH (eds). Modelling the impact of climate change on rice production in Asia. IRRI/CAB International, Wallingford, pp 217-235

Dorfer V, Pichler P, Stranzl T, Stadlmann J, Taus T, Winkler S, Mechtler K (2014) MS amanda, a universal identification algorithm optimised for high accuracy tandem mass spectra. J Proteome Res 13(8):3679-3684. doi:10.1021/pr500202e
Ebitani T, Yamamoto Y, Yano M, Funane M (2008) Identification of quantitative trait loci for grain appearance using chromosome segment substitution lines in rice. Breed Res 10:91-99. doi:10.1111/j.1744-7909.2009.00822.x

Echevarría-Zomeño S, Fernández-Calvino L, Castro-Sanz AB, López JA, Vázquez J ، Castellano MM (2015) Dissecting the proteome dynamics of the early heat stress response leading to plant survival or death in Arabidopsis. Plant Cell Environ. doi:10.1111/pce.12664

Emes MJ, Bowsher CG, Hedley C, Burrell MM, E. Scrase-Field ESF, Tetlow IJ (2003) Starch synthesis and carbon partitioning in developing endosperm. J Exp Bot 54:569-75. doi:10.1093/jxb/erg089

Evers D, Juliano BO (1976) Varietal differences in surface ultrastructure of endosperm cells and starch granules of rice. Starch/Stärke 28:160-166

Fujita N, Hanashiro I, Suzuki S, Higuchi T, Toyosawa Y, Utsumi Y, Itoh R, Aihara S, Nakamura $Y$ (2012) Elongated phytoglycogen chain length in transgenic rice endosperm expressing active starch synthase lla affects the altered solubility and crystallinity of the storage a-glucan. J Exp Bot 63:5859-5872. doi:10.1093/jxb/ers235

Fuwa H, Glover DV, Sugimoto Y (1977) Scanning electron microscopic observations of degradation of starch granules in germinating kernels of several maize (Zea mays L.) endosperm mutants in four inbred and one hybrid background and their normal counterparts. J Jpn Soc Starch Sci 24:99-111

Guglielminetti L, Yamaguchi J, Perata P, Alpi A (1995) Amylolytic activities in cereal seeds under aerobic and anaerobic conditions. Plant Physiol 109: 1069-1076

Hakata M, Kuroda M, Miyashita T, Yamaguchi T, Kojima M, Sakakibara H, Mitsui T, Yamakawa H (2012) Suppression of a-amylase genes improves quality of rice grain ripened under high temperature. Plant Biotechnol J 10:1110-7. doi:10.1111/j.1467-7652.2012.00741.x

Hamaker BR (1994) The influence of rice protein on rice quality. In: Marshall WE, Wadsworth J (eds) Rice science and technology. Dekker, New York, pp 177-194

He P, Li SG, Qian Q, Ma YQ, Li JZ, Wang WM, Chen Y, Zhu LH (1999) Genetic analysis of rice grain quality. Theor Appl Genet 98:502-508

Ingram J, Bartels D (1996) The molecular basis of dehydration tolerance in plants. Annu Rev Plant Physiol Plant Mol Biol 47:377-403

Inouchi N, Ando H, Asaoka M, Okuno K, Fuwa H (2000) The effect of environmental temperature on distribution of unit chains of rice amylopectin. Starch/Stärke 52:8-12. doi:10.1002/(SICI)1521-379X(200001) 52:1<8::AID-STAR8>3.0.CO;2-Q

IPCC (2013) Climate Change 2013: The Physical Science Basis. Summary for Policymakers. Contribution of Working Group I to the Fifth Assessment Report of the Intergovernmental Panel on Climate Change. In: Stocker TF, Qin D, Plattner G-K et al. (eds). Cambridge, Cambridge University Press, pp 1-27

Ishiamaru T, Hirabayashi H, Sasaki K, Ye C, Kobayashi A (2016) Breeding efforts to mitigate damage by heat stress to spikelet sterility and grain quality. Plant Prod Sci 19:12-21

Ishimaru T, Horigane AK, Ida M, Iwasawa N, San-oh YA, Nakazono M, Nishizawa NK, Masumura T, Kondo M, Yoshida M (2009) Formation of grain chalkiness and changes in water distribution in developing rice caryopses grown under hightemperature stress. J Cereal Sci 50:166-174

Itayagoshi S, Mizusawa S, Kawakami O, Shibukawa H, Takamatsu T, Sasaki M, Kaneko K, Mitsui T (2015) Suppressive effects of low seed-soaking temperatures on germination of long-term-stored rice seeds. Plant Prod Sci 18:455-463

Iwasawa N, Umemoto T, Hiratsuka M, Nitta Y, Matsuda T, Kondo M (2009) Structural characters of milky-white rice grains caused by high temperature and shading during grain-filling. Jpn J Crop Sci 78:322-323. doi:10.14829/jcsproc.227.0.330.0

Jagadish SVK, Craufurd PQ, Wheeler TR (2008) Phenotyping parents of mapping populations of rice (Oryza sativa L.) for heat tolerance during anthesis. Crop Sci 48:1140-1146

Kanno K, Makino A (2010) Increased grain yield and biomass allocation in rice under cool night temperature. Soil Sci Plant Nutr 56:412-417

Kim SS, Lee SE, Kim OW, Kim DC (2000) Physicochemical characteristics of chalky kernels and their effects on sensory quality of cooked rice. Cereal Chem 77:376-379

Kobayashi A, Sonoda J, Sugimoto K, Kondo M, Iwasawa N, Hayashi T, Tomita K, Yano M, Shimizu T (2013) Detection and verification of QTLs associated with heat-induced quality decline of rice (Oryza sativa L.) using recombinant inbred lines and near-isogenic lines. Breed Sci 63:339-346. doi:10.1270/jsbbs.63.339

Koller A, Washburn MP, Lange BM, Andon NL, Deciu C, Haynes PA, Hays L, Schieltz D, Ulaszek R, Wei J, Wolters D, Yates JR (2002) Proteomic survey of 
metabolic pathways in rice. Proc Natl Acad Sci U S A 99:11564-11566. doi:10.1073/pnas.172183199

Lee J, Koh HJ (2011) A label-free quantitative shotgun proteomics analysis of rice grain development. Proteome Sci 9:61. doi:10.1186/1477-5956-9-61

Li J, Xiao J, Grandillo S, Jiang L, Wan Y, Deng Q, Yuan L, McCouch SR (2004) QTL detection for rice grain quality traits using an interspecific backcross population derived from cultivated Asian (O. sativa L.) and African (O. glaberrima S.) rice. Genome 47:697-704

Liao JL, Zhou HW, Zhang HY, Zhong PA, Huang YJ (2013) Comparative proteomic analysis of differentially expressed proteins in the early milky stage of rice grains during high temperature stress. J Exp Bot 65:655-671. doi:10.1093/jxb/ert435

Lin SK, Chang MC, Tsai YG, Lur HS (2005) Proteomic analysis of the expression of proteins related to rice quality during caryopsis development and the effect of high temperature on expression. Proteomics 5:2140-2156. doi:10.1002/pmic.200401105

Lin CJ, Li CY, Lin SK, Yang FH, Huang JJ, Liu YH, Lur HS (2010) Influence of high temperature during grain filling on the accumulation of storage proteins and grain quality in rice (Oryza sativa L.). J Agric Food Chem 58:10545-10552

Lin Z, Zhang X, Yang X, Li G, Tang S, Wang S, Ding Y, Liu Z (2014) Proteomic analysis of proteins related to rice grain chalkiness using iTRAQ and a novel comparison system based on a notched-belly mutant with white-belly. BMC Plant Biol 14:163. doi:10.1186/1471-2229-14-163

Lisle AJ, Martin M, Fitzgerald MA (2000) Chalky and translucent rice grains differ in starch composition and structure and cooking properties. Cereal Chem 77:627-632

Liu L, Hu X, Song J, Zong X, Li D (2009) Over-expression of a Zea mays L. protein phosphatase $2 \mathrm{C}$ gene (ZmPP2C) in Arabidopsis thaliana decreases tolerance to salt and drought. J Plant Phys 166:531-542

Liu X, Guo T, Wan X, Wang H, Zhu M, Li A, Su N, Shen Y, Mao B, Zhai H, Mao L, Wan J (2010) Transcriptome analysis of grain-filling caryopses reveals involvement of multiple regulatory pathways in chalky grain formation in rice. BMC Genomics 11:730. doi:10.1186/1471-2164-11-730

Liu X, Wan X, Ma X, Wan J (2011) Dissecting the genetic basis for the effect of rice chalkiness, amylose content, protein content, and rapid viscosity analyzer profile characteristics on the eating quality of cooked rice using the chromosome segment substitution line population across eight environments. Genome 54:64-80

Luo M, Liu J, Lee RD, Scully BT, Guo B (2010) Monitoring the expression of maize genes in developing kernels under drought stress using oligo-microarray. J Integr Plant Biol 52:1059-1074. doi:10.1111/j.1744-7909.2010.01000.x

McClung JK, King RL, Walker LS, Danner DB, Nuell MJ, Stewart CA, Dell'Orco RT (1992) Expression of prohibitin, an antiproliferative protein. Exp Gerontol 27:413-417

McClung JK, Jupe ER, Liu XT, Dell'Orco RT (1995) Prohibitin: potential role in senescence, development, and tumor suppression. Exp Gerontol 30:99-124

Mei DY, Zhu YJ, Yu YH, Fan YY, Huang DR, Zhuang JY (2013) Quantitative trait loci for grain chalkiness and endosperm transparency detected in three recombinant inbred line populations of indica rice. J Integr Agr 12:1-11

Meyer RF, Boyer JS (1981) Osmoregulation, solute distribution and growth in soybean seedlings having low water potentials. Planta 151:482-489

Milioni D, Hatzopoulos P (1997) Genomic organization of hsp90 gene family in Arabidopsis. Plant Mol Biol 35:955-961. doi:10.1023/A:1005874521528

Mitsui T, Yamaguchi J, Akazawa T (1996) Physicochemical and serological characterization of rice a-amylase isoforms and identification of their corresponding genes. Plant Physiol 110:1395-1404

Mitsui T, Yamakawa H, Kobata T (2016) Molecular physiological aspects of chalking mechanism in rice grains under high-temperature stress. Plant Prod Sci 19:22-29

Mohammadi R, Mozaffar RM, Yousef A, Mostafa A, Amri A (2010) Relationships of phenotypic stability measures for genotypes of three cereal crops. Can J Plant Sci 90:819-830

Morgan JM (1977) Differences in osmoregulation between wheat genotypes. Nature 270:234-235

Morimoto RI (2002) Dynamic remodeling of transcription complexes by molecular chaperones. Cell 110:281-284

Morita S, Yonemaru J, Takanashi J (2005) Grain growth and endosperm cell size under high night temperatures in rice (Oryza sativa L.). Ann Bot 95: 695-701

Morita S, Wada H, Matsue Y (2016) Countermeasures for heat damage in rice grain quality under climate change. Plant Prod Sci 19:1-11
Muench DG, Wu Y, Zhang Y, Li X, Boston RS, Okita TW (1997) Molecular cloning, expression and subcellular localization of a BiP homolog from rice endosperm tissue. Plant Cell Physiol 38:404-412. doi:10.1093/oxfordjournals.pcp.a029183

Næsted H, Frandsen Gl, Jauh GY, Hernandez-Pinzon I, Nielsen HB, Murphy D, Rogers JC, Mundy J (2000) Caleosins: $\mathrm{Ca}^{2+}$ binding proteins associated with lipid bodies. Plant Mol Biol 44:463-476

Nagato K, Ebata M (1965) Effects of high temperature during ripening period on the development and the quality of rice kernels. Jpn J Crop Sci 34:59-66

Nanjo Y, Asatsuma S, Itoh K, Hori H, Mitsui T (2004) Proteomic identification of a-amylase isoforms encoded by RAmy3B/3C from germinating rice seeds. Biosci Biotechnol Biochem 68:112-118

Nijtmans L, Artal-Sanz M, Grivell L, Coates P (2002) The mitochondrial PHB complex: roles in mitochondrial respiratory complex assembly, ageing and degenerative disease. Cell Mol Life Sci 59:143-155

Nishi A, Nakamura Y, Tanaka N, Satoh H (2001) Biochemical and genetic analysis of the effects of amylose-extender mutation in rice endosperm. Plant Physiol 127:459-472. doi:10.1104/pp.010127

O'Shea MG, Morell MK (1996) High resolution slab gel electrophoresis of 8-amino-1,3, 6-pyrenetrisulfonic acid (APTS) tagged oligosaccharides using a DNA sequencer. Electrophoresis 17:681-688s

Olvera-Carrillo Y, Reyes JL, Covarrubias AA (2011) Late embryogenesis abundant proteins: Versatile players in the plant adaptation to water limiting environments. Plant Signal Behav 6:586-589. doi:10.4161/psb.6.4.15042

Phan TTT, Ishibashi Y, Miyazaki M, Tran MHT, Okamura K, Tanaka S, Nakamura J, Yuasa T, Iwaya-Inoue M (2013) High temperature-induced repression of the rice sucrose transporter (OSSUT1) and starch synthesis-related genes in sink and source organs at milky ripening stage causes chalky grains. J Agron Crop Sci 199:178-188. doi:10.1111/jac.12006

Piper P, Jones G, Bringloe D, Harris N, MacLean M, Mollapour M (2002) The shortened replicative life span of prohibitin mutants of yeast appears to be due to defective mitochondrial segregation in old mother cells. Aging Cell 1: $149-157$

Poxleitner M, Rogers SW, Samuels AL, Browse J, Rogers J (2006) A role for caleosin in degradation of oil-body storage lipid during seed germination. Plant J 47:917-933. doi:10.1111/j.1365-313X.2006.02845.X

Ray DK, Gerber JS, MacDonald GK, West PC (2015) Climate variation explains a third of global crop yield variability. Nat Commun 6:5989. doi:10.1038/ncomms6989

Scarpeci TE, Zanor MI, Valle EM (2008) Investigating the role of plant heat shock proteins during oxidative stress. Plant Signal Behav 3:856-7

Shi W, Muthurajan R, Rahman H, Selvam J, Peng S, Zou Y, Jagadish KSV (2013) Source-sink dynamics and proteomic reprogramming under elevated night temperature and their impact on rice yield and grain quality. New Phytol 197:825-837. doi:10.1111/nph.12088

Shiraya T, Mori T, Mruyama T, Sasaki M, Takamatsu T, Oikawa K, Kaneko K, Itoh K, Ichikawa H, Mitsui T (2015) Golgi/plastid-type manganese superoxide dismutase involved in heat-stress tolerance during grain filling of rice. Plant Biotechnol J 13:1251-1263. doi:10.1111/pbi.12314

Singh N, Sodhi NS, Kaur M, Saxena SK (2003) Physicochemical, morphological, thermal, cooking and textural properties of chalky and translucent rice kernels. Food Chem 82:433-439

Su J-C (2000) Starch synthesis and grain filling in rice. In: Gupt AK and Kaur N (eds). Carbohydrate Reserves in Plants - Synthesis and Regulation. Amsterdam, The Netherlands, Elsevier, pp 107-124

Tabata M, Hirabayashi H, Takeuchi Y, Ando I, lida Y, Ohsawa R (2007) Mapping of quantitative trait loci for the occurrence of white-back kernels associated with high temperatures during the ripening period of rice (Oryza sativa L.). Breed Sci 57:47-52

Tanaka N, Fujita N, Nishi A, Satoh H, Hosaka Y, Ugaki M, Kawasaki S, Nakamura Y (2004) The structure of starch can be manipulated by changing the expression levels of starch branching enzyme Ilb in rice endosperm. Plant Biotechnol J 2:507-16. doi:10.1111/j.1467-7652.2004.00097.x

Tashiro T, Wardlaw IF (1990) The response to high temperature shock and humidity changes prior to and during the early stages of grain development in wheat. Aust J Plant Physiol 17:551-561

Tashiro T, Wardlaw IF (1991) The effect of high temperature on the accumulation of dry matter, carbon and nitrogen in the kernel of rice. Aust J Plant Physiol 18:259-265

Tatsuta T, Model K, Langer T (2005) Formation of membrane-bound ring complexes by prohibitins in mitochondria. Mol Biol Cell 16:248-259. doi:10.1091/mbc.E04-09-0807 
Tsutsui K, Kaneko K, Hanashiro I, Nishinari K, Mitsui T (2013) Characteristics of opaque and translucent parts of high temperature stressed grains of rice. J Appl Glycosci. doi:10.5458/jag.jag.JAG-2012014

Tsuyukubo M, Ookura T, Tsukui S, Mitsui T, Kasai M (2012) Elution behavior analysis of starch degrading enzymes during rice cooking with specific antibodies. Food Sci Technol Res 18:659-666

Umemoto T, Terashima K (2002) Activity of granule-bound synthase is an important determinant of amylose content in rice endosperm. Funct Plant Biol 29:1121-1124

Usui Y, Sakai H, Tokida T, Nakamura H, Nakagawa H, Hasegawa T (2014) Heat-tolerant rice cultivars retain grain appearance quality under free-air $\mathrm{CO}_{2}$ enrichment. Rice 7:6. doi:10.1186/s12284-014-0006-5

van Aken O, Zhang BT, Carrie C, Uggalla V, Paynter E, Giraud E, Whelan J (2009) Defining the mitochondrial stress response in Arabidopsis thaliana. Mol Plant 2:1310-1324. doi:10.1093/mp/ssp053

Wada H, Masumoto-Kubo C, Gholipour Y, Nonami H, Tanaka F, Erra-Balsells R, Tsutsumi K, Hiraoka K, Morita S (2014) Rice chalky ring formation caused by temporal reduction in starch biosynthesis during osmotic adjustment under foehn-induced dry wind. PLoS One 9:e1 10374. doi:10.1371/journal. pone. 0110374

Wan XY, Wan JM, Weng JF, Jiang L, Bi JC, Wang CM, Zhai HQ (2005) Stability of QTLs for rice grain dimension and endosperm chalkiness characteristics across eight environments. Theor Appl Genet 110:1334-1346

Wang W, Vinocur B, Shoseyov O, Altman A (2004) Role of plant heat-shock proteins and molecular chaperones in the abiotic stress response. Trends Plant Sci 9:244-252

Xiao B, Huang Y, Tang N, Xiong L (2007) Over-expression of a LEA gene in rice improves drought resistance under the field conditions. Theor Appl Genet 115:35-46. doi:10.1007/s00122-007-0538-9

Xu SB, Li T, Deng ZY, Chong K, Xue Y, Wang T (2008) Dynamic proteomic analysis reveals a switch between central carbon metabolism and alcoholic fermentation in rice filling grains. Plant Physiol 148:908-925

Yamakawa H, Hirose T, Kuroda M, Yamaguchi T (2007) Comprehensive expression profiling of rice grain filling-related genes under high temperature using DNA microarray. Plant Physiol 144:258-277. doi:10.1104/pp.107.098665

Yasuda H, Hirose S, Kawakatsu T, Wakasa Y, Takaiwa F (2009) Overexpression of BiP has inhibitory effects on the accumulation of seed storage proteins in endosperm cells of rice. Plant Cell Physiol 50:1532-43. doi:10.1093/pcp/pcp098

Zakaria S, Matsuda T, Tajima S, Nitta Y (2002) Effect of high temperature at ripening stage on the reserve accumulation in seed in some rice cultivars. Plant Prod Sci 5:160-168. doi:10.1626/pps.5.160

Zeng T, Jiang X, Li J, Wang D, Li G, Lu L, Wang G (2013) Comparative proteomic analysis of the hepatic response to heat stress in Muscovy and Pekin ducks: insight into thermal tolerance related to energy metabolism. PLoS One 8:e76917. doi:10.1371/journal.pone.0076917

Zheng BS, Rönnberg E, Viitanen L, Salminen TA, Lundgren K, Morita T, Edqvist J (2008) Arabidopsis sterol carrier protein-2 is required for normal development of seeds and seedlings. J Exp Bot 59:3485-3499. doi:10.1093/jxb/ern201

Zi J, Zhang J, Wang Q, Zhou B, Zhong J, Zhang C, Qiu X, Wen B, Zhang S, Fu X, Lin L, Liu S (2013) Stress responsive proteins are actively regulated during rice (Oryza sativa) embryogenesis as indicated by quantitative proteomics analysis. PLoS One 8:e74229. doi:10.1371/journal.pone.0074229

\section{Submit your manuscript to a SpringerOpen ${ }^{\circ}$ journal and benefit from:}

- Convenient online submission

- Rigorous peer review

- Immediate publication on acceptance

- Open access: articles freely available online

- High visibility within the field

Retaining the copyright to your article

Submit your next manuscript at $\boldsymbol{s p r i n g e r o p e n . c o m ~}$ 